\title{
Çocuk Sağlığı ve Hastalıkları Uzmanlarının COVID-19 Pandemisinin Erken Döneminde Yapılan Uzaktan Eğitim Sonrası Bilgi ve Tutumları
}

\section{The Knowledge and Attitudes of Pediatricians After Distance Education in The Early Period of The Covid-19 Pandemic}

\author{
Erdem Gönüllü̈ ${ }^{1}$ [D \\ ${ }^{1}$ istanbul Sağlık ve Teknoloji Üniversitesi, Tıp Fakültesi, Çocuk Sağlığı ve Hastalıkları Anabilim Dalı, İstanbul, Türkiye
}

ORCID ID: E.G. 0000-0002-6833-5646

Attf/Citation: Gonullu E. Çocuk sağlığı ve hastalıkları uzmanlarının COVID-19 pandemisinin erken döneminde yapılan uzaktan eğitim sonrası bilgi ve tutumları. Çocuk Dergisi - Journal of Child 2021;21(2):157-160. https://doi.org/10.26650/jchild.2021.2.939509

öz

Amaç: 2020 yılı başında patlak veren COVID-19 salgını yaşamda, çalışma ve eğitim hayatında kökten değişikliklere neden olmuştur. Bu değişikliklerin, pandeminin odağında olan sağılı çalışanlarını etkilememesi mümkün değildir. Mezuniyet sonrası klasik öğrenme imkanlarının azalması üzerine Çocuk Sağlığı ve Hastalıkları uzmanlarının gönüllü katııımıla kurulan Pediatri Atölyesi üzerinden bir grup pediatrist çevrimiçi yardımlaşma ve bilgi paylaşımını daha sistematik hale getirmiş ve COVıD-19 salgınının erken döneminde etkin bir bilgilendirme çalışması yürütmüşlerdir. Bilgilendirme çalışması sonrası hekimlerinin bilgi ve tutumlarını değerlendirerek uzaktan eğitimin yarattığı değişikliği göstermek hedeflenmiştir. Gereç ve Yöntem: Bu amaçla yapılan ilk kitlesel çevrimiçi yayından sonra yapılan çevrimiçi anket uygulaması ile grubun demografik verileri saptanmıştır.

Bulgular: Ankete cevap veren katılımcıların ( $n=437) 146$ 'sı (\%33) 28-35 yaş,171'i (\%39) 36-44 yaş, 109'u (\%25) 45-60 yaş aralığında ve $11^{\prime} i$ i (\%3) 61 yaşından büyüktü. Eğitim sonrası ankete cevap veren katılımcıların 279 'u (\%64) kadındı. Anket katılımcılarının 44'ü (\%10) yan dal uzmanıydı. Katılımcılara eğitim öncesi COVID-19 ile bilgileri hangi kaynaktan edindikleri sorulduğunda, 388'i $(\% 88,7)$ Sağlık Bakanlığının, 204'ü $(\% 46,6)$ Dünya Sağlık Örgütünün bilgilendirmelerini izlediğini, 383'ü $(\% 87,6)$ Pediatri Atölyesinin yazışma ve programlarını izlediğini, 105'i (\%24) Hastalık Kontrol Merkezi $(C D C)$ ve $113^{\prime}$ ü $(\% 25,8)$ de PubMed üzerinden literatür takip ettiğini belirtmiştir.

COVID-19 aşısı gelirse, katılımcıların 323'ü $(\% 73,9)$ aşıyı kendisine ve çocuklarına yaptıracağını, 58'i $(\% 13,3)$ aşıyı sadece kendisine yaptıracağını, $44^{\prime}$ ü $(\% 10,1)$ aşıyı kendisine ve çocuklarına yaptırmayacağını belirtmiştir. Sonuç: Daha öncesinde planlaması yapılmamı̧ ve heterojen yapıya sahip bir öğrenici kitlesinde bile, uzaktan eğitim, hedef kitlenin bilgi düzeyini artırabilir. Pediatri Atölyesi gibi topluluklar özellikle bilgiye ulaşımı coğrafi, ekonomik ve olağandışı koşullar nedeni ile asimetrik olan hekim grubu için olumlu bir rol oynayabilir.

Anahtar Kelimeler: COVID-19, uzaktan eğitim, pandemi
ABSTRACT

Objective: The COVID-19 epidemic started at the beginning of 2020, and has caused radical changes in life, work, and education. The possibility of breaking the educational efforts of affected healthcare workers at the center of the pandemic is a reality. The Pediatrics Atelier was established with the voluntary participation of pediatricians after graduation. A group of pediatricians made online cooperation and information sharing more systematic, and carried out practical information early in the COVID-19 epidemic. After the informative study, we planned a study to show the change created by distance education by evaluating the knowledge and attitudes of physicians.

Material and Method: The demographic data of the group was determined with the online survey application made after the first online broadcast for this purpose.

Results: Of the respondents ( $n=437), 146(33 \%)$ were $28-35$ years old, 171 (39\%) were $36-44$ years old, 109 (25\%) were $45-60$ years old, and 11 (3\%) were over 61 years old. Of the participants who responded to the posttraining questionnaire, $279(64 \%)$ were women. Forty-four (10\%) of the survey participants were minor specialists. When the participants were asked from which source they got the information about COVID-19 before the training, 388 (88.7\%) of them followed the information of the Ministry of Health, 204 (46.6\%) of them followed the information of the World Health Organization, and 383 (87.6\%) of them were Pediatrics. They stated that they followed the correspondence and programs of the workshop; 105 (24\%) followed the literature via the Center for Disease Control (CDC) and $113(25.8 \%)$ via PubMed.

If the COVID-19 vaccine is offered, $323(73.9 \%)$ of the participants have declared they would get the vaccine for themselves and their children, 58 (13.3\%) said they would only get the vaccine for themselves, and 44 $(10.1 \%)$ said would not get the vaccine for themselves or their children. Conclusion: Even in an unplanned and heterogeneous population, distance education can increase the knowledge level of the target group. Communities such as the Pediatrics Atelier can play a positive role, especially for the physician group whose access to information is asymmetrical due to geographical, economic, and unusual conditions.

Keywords: COVID-19, Distance education, pandemic

Sorumlu Yazar/Corresponding Author: Erdem Gönüllü E-mail: erdemgon@gmail.com

Başvuru/Submitted: 19.05.2021 • Revizyon Talebi/Revision Requested: 22.06.2021 • Son Revizyon/Last Revision Received: $12.07 .2021 \bullet$ Kabul/Accepted: 13.07.2021 
GiRiş

COVID-19 salgını, 2020 yılının ilk çeyreğinden itibaren tüm dünyayı etkisi altına almış ve Dünya Sağlık Örgütü (DSÖ) tarafindan Pandemi olarak adlandırılmıştır (1). Bu süreçte, Türkiye'de de ilk olgunun 11.3.2020 tarihinde görüldüğü açıklanmış, sonrasında salgın kısa sürede ülkemizi de etkisi altına almıştır (2). Yeni tip koronavirüs hastalığına (COVID-19) salgınının başlangıcından 3 Aralık 2020'ye kadar küresel olarak COVID-19'a bağlı 100 milyondan fazla doğrulanmış enfeksiyon ve 2 milyondan fazla kayıp bildirilmiştir (1).

Türkiye'de ilk doğrulanmış COVID-19 vakası 11 Mart 2020 tarihinde Sağlık Bakanlığı tarafindan rapor edilmiş ve 16 Aralık 2020 tarihine kadar, sıkı pandemi kontrolüne rağmen toplam 1928165 doğrulanmış vaka ve 17121 ölüm bildirilmiştir (2). Hastalık tüm ülkelere yayılmış, her bireyi ve çocuğu bir şekilde etkilemektedir. Sağlık çalışanları salgında en ön safta savaşmış ve hastalıkla ilişkili en riskli grupta yer almış, 2 Aralık 2019'dan bu yana, dünya çapında yaklaşık yüz bin sağlık çalışanı şiddetli akut solunum zorluğu sendromu yapan Koronavirüs- Tip 2 (SARS-CoV-2) ile enfekte olmuştur (3). Aralık 2020'de Türkiye Cumhuriyeti Sağlık Bakanlığı, Türkiye'de enfekte sağlık sektörü çalışanlarının sayısının 120000'i aştığını ve 216 sağlık çalışanının COVID-19 nedeniyle hayatını kaybettiğini açıklamıştır (2).

Etkin aşılamaya değin hastalığın yayılımını önlemenin yolu; etkenin bulaş yollarını bilmek ve sağlık çalışanlarına da bu bilgiyi ulaştırmaktır. COVID-19 aşılarının kabul edilmesi, bu nedenle salgının yayılımını önlemede önemlidir (4).

Yeni keşfedilen bir etken hakkında yeni veya değişen bilgiler ve özellikle korunma ile ilgili gerekli bilgi paylaşımı ile önlem alınması ve tutum değişikliklerin yapılabilmesi için sürekliliği olan bir eğitim gereklidir (5). Salgın sürecinde mezuniyet sonrası tip eğitimi de sekteye uğramış, geleneksel yöntemle yapılagelen kongreler önce ertelenmiş sonrasında ise iptal edilmiştir. Pandeminin kısa sürede bitmeyeceği görüldükten sonra çoğu uzmanlık dalı kongrelerini yüz yüze yönteminden çevrimiçi yönteme çevirmiştir.

Çocuk Sağlığı ve Hastalıkları ile uğraşan hekimler, bu süreçte COVID-19 ile ilişkili bilgileri değişik mecralardan almaktadır. Bu bilgilerin bir kısmı klasik basılı ve elektronik ortamdaki yazılı metinlerden, bir kısmı ise sözel-görsel eğitimlerden edinilmektedir. Pandemi sırasında yüz yüze eğitim olasılığı kalmasa da çevrimiçi eğitim amacı ile kurulan grupların, diğer uzmanlık grupları için olduğu kadar, pediatri eğitimi için de yeni bir eğitim aracı olarak kullanılabileceği anlaşılmıştır. Salgından hemen önce kurulan Pediatri Atölyesi, bu mecralardan biri olabilir (6).

Pediatri atölyesi, pediatrik enfeksiyon hastalıkları ve diğer akademisyen pediatrist konsültasyonlar ve topluluğa açık çevrimiçi toplantilar yoluyla COVID-19 hakkında öneri ve bilgilendirmeler yapmıştır. COVID-19 ilişkili ilk yayın, 19.3.2020 tarihinde YouTube üzerinden yapılmış, sonrasında Atölye üyesi Çocuk Sağlığı ve Hastalıkları uzmanlarına çevrimiçi bir anket uygulanarak salgının erken dönemindeki bilgi ve tutumlarını incelemek amacı ile kesitsel bir çalışma kurgulanmıştır.

\section{GEREÇ VE YÖNTEM}

Google formlar kullanılarak, eğitimden iki hafta sonrasında (3.4.2020-9.4.2020) Pediatri Atölye üyelerine yönelik bir anket çalışması yapılmıştır, sonuçlar Jamovi istatistiksel veri işleme programı ile değerlendirilmiş ve grup demografik özellikleri belirlenmiştir (7).

\section{BULGULAR}

Çalışma anketlerine, Türkiye'nin yedi bölgesinde yer alan 71 ilinden, KKTC Girne, Azerbaycan-Bakü ve ABD New Jersey'den birer olmak üzere toplam 437 kişi cevap vermiştir. Grubun aktif üye sayısına göre ankete geri dönüş oranı $\% 43$ idi.

Eğitim sonrası ankete cevap veren katilımcıların ( $n=437) 146$ 'sı (\%33) 28-35 yaş,171'i (\%39) 36-44 yaş, 109'u (\%25) 45-60 yaş aralığında ve $11^{\prime} i$ (\%3) 61 yaşından büyüktü. Eğitim sonrası ankete cevap veren katılımcıların 279'u (\%64) kadındı. Anket katılımcılarının 44'ü (\%10) yandal uzmanıydı. Katılımcıların demografik özellikleri Tablo 1'de özetlenmiştir.

Tablo 1: Katılımcıların demografik özellikleri.

\begin{tabular}{|c|c|c|}
\hline & Sayı (n) & $\%$ \\
\hline & 437 & \\
\hline \multicolumn{3}{|l|}{ Yaş } \\
\hline $28-35$ & 146 & 33 \\
\hline $36-44$ & 171 & 39 \\
\hline $45-60$ & 109 & 25 \\
\hline$>61$ & 11 & 3 \\
\hline \multicolumn{3}{|l|}{ Cinsiyet } \\
\hline Kadın & 279 & 64 \\
\hline Erkek & 158 & 36 \\
\hline \multicolumn{3}{|l|}{ Uzmanlık } \\
\hline Pediatri Uzmanı & 393 & 90 \\
\hline Pediatri Yandal Uzmanı & 44 & 10 \\
\hline \multicolumn{3}{|l|}{ Uzmanlık Süresi } \\
\hline $1-5 \mathrm{yll}$ & 181 & 41 \\
\hline $6-10$ yıl & 85 & 19 \\
\hline 11-15 yıl & 62 & 14 \\
\hline$>15$ yıl & 109 & 25 \\
\hline \multicolumn{3}{|l|}{ Unvan } \\
\hline Profesör & 6 & 1 \\
\hline Doçent & 14 & 3 \\
\hline Dr. Öğr. Üyesi & 14 & 3 \\
\hline Uzman Dr. & 403 & 93 \\
\hline \multicolumn{3}{|l|}{ Çalışılan Kurum } \\
\hline Özel Sağlık Kurumu & 166 & 38 \\
\hline Kamu Sağlık Kurumu & 174 & 49 \\
\hline Muayenehane & 20 & 5 \\
\hline Üniversite / EAH & 77 & 18 \\
\hline
\end{tabular}


Katlımcılara eğitim öncesi COVID-19 ile bilgileri hangi kaynaktan edindikleri, eğitim sonrası COVID-19 tedavisi için bilinen tedaviler, COVID-19 hastalığından şüphelendiren belirtiler, tanı kriteri olmayan belirtiler, hastalara korunma amaçlı verilen öneriler ve ilaç destekleri, COVID-19'un gündelik yaşam üzerine etkileri ve son olarak cevap verenlerin COVID-19 şüpheli hasta görüp görmedikleri ve sevk edip etmedikleri sorulmuştur, cevaplar Tablo 2'de özetlenmiştir.

COVID-19 aşısı gelirse, katılımcıların 323'ü $(\% 73,9)$ aşıyı kendisine ve çocuklarına yaptıracağını, 58'i $(\% 13,3)$ aşıyı sadece kendisine yaptıracağını, 44'ü $(\% 10,1)$ aşıyı kendisine ve çocuklarına yaptırmayacağını belirtmiştir.

Eğitim sonrası katılımcılara COVID-19 hastalığının belirtileri ve kliniği, hastalık için risk faktörleri, etkenin ana ve ara konağı, hastalığın inkübasyon süresi ve önerilen izolasyon süresi, mortalite oranı, etkenin vertikal ve anne sütü ile geçişi konularını içeren kapalı uçlu sorular sorulmuştur. Verilen yanıtlar üzerinden eğitim sonrası anketi cevaplayanların bilgi düzeyi değerlendirilmiş, verilen yanıtlar Tablo 3'te sunulmuştur.

\section{TARTIŞMA}

COVID-19 nedeniyle gerçekleşen geleneksel öğrenme dinamiklerindeki ani bir değişiklik, pediatristlerin sadece gündelik çalışma rutinlerini değiştirmekle kalmamış, aynı zamanda yeni öğrenme tekniklerini uygulamaya da motive etmiş görünmektedir. Çalışmamızın sonuçlarına dayanarak, ortaya çıkan yeni bir salgının kliniği ve korunma yolları hakkında değişik kaynaklardan bilgi edinme yeteneği çocuk hekimlerinde Pediatri Atölyesi öncesinde de halihazırda mevcuttur. Pediatri Atölyesinin çevrimiçi etkinlikleri, mezuniyet sonrası çocuk hekimlerinin güncel bilgiye ulaşmasını sağlamak için çok etkili bir yöntem gibi görünmektedir. Anket sonunda çoğu çocuk hekimi bu yöntemin öğrenmeye elverişli bir ortam sağladığını, periferde güncel anadilde bilgiye daha kolay erişebildiklerini, gerektiğinde eğitmenle iletişim kurabildikleri şeklinde geri bildirimler vermiştir.

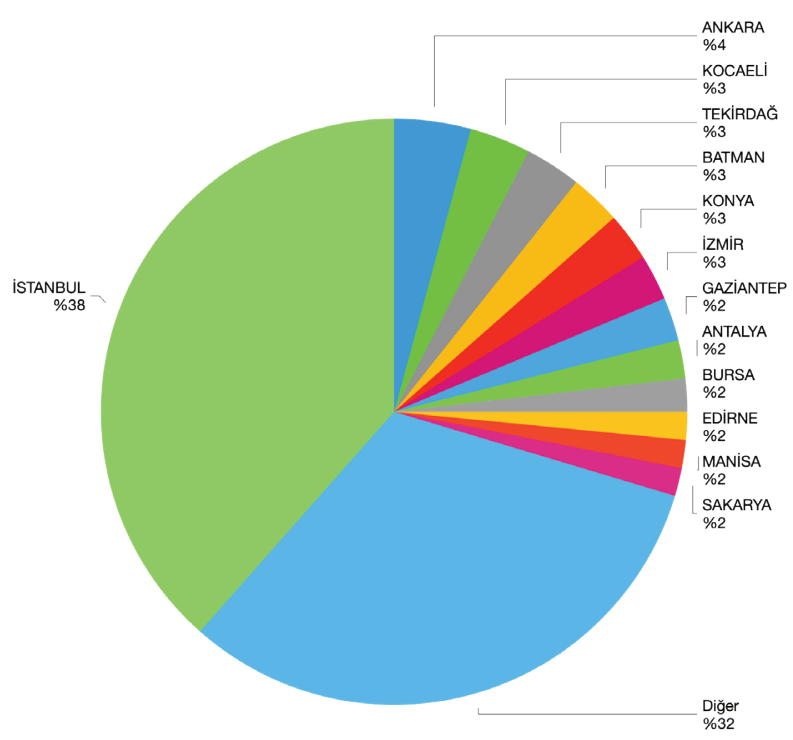

Şekil 1: Katılımcıların illeri.
Tablo 2: Katılımcıların anket cevaplarının dağılımı.

\begin{tabular}{lcc}
\hline & $\mathbf{n}$ & $\%$ \\
\hline COVID-19 ile bilgileri hangi kaynaktan ediniyorsunuz? & & \\
Sağlık Bakanlığı & 388 & 88,7 \\
Dünya Sağlık Örgütü & 204 & 46,6 \\
Pediatri Atölyesi & 383 & 87,6 \\
Hastalık Kontrol Merkezi- CDC & 105 & 24 \\
PubMed - Literatür takibi & 113 & 25,8 \\
COVID-19 için bildiğiniz tedaviler nelerdir? & & \\
Oseltamivir & 266 & 60,8 \\
Ritonavir/Lopinavir & 423 & 96,7 \\
Kinin & 305 & 69,7 \\
Remdesivir & 346 & 79,1 \\
Kortikosteroid & 152 & 34,7 \\
IVIG & 196 & 44,8
\end{tabular}

COVID-19 hastalığından şüphelendiren belirtiler nelerdir?

Son 14 gün içinde hastalıklı kişiyle temas $\quad 420 \quad 96,1$

Son 14 gün içinde yurtdışından gelen bireyle temas $419 \quad 95,8$ öyküsü

$\begin{array}{lll}\text { Ateş } & 433 \quad 99\end{array}$

$\begin{array}{lll}\text { Öksürük } & 429 & 98,1\end{array}$

COVID-19 için tanı kriteri olmayan belirtiler nelerdir?

$\begin{array}{lrr}\text { Ateş } & 8 & 1,8\end{array}$

$\begin{array}{lll}\text { Öksürük } & 9 & 2\end{array}$

$\begin{array}{lll}\text { Nefes darlığı } & 8 & 1,8\end{array}$

$\begin{array}{lll}\text { Burun akıntısı } & 401 & 91,7\end{array}$

$\begin{array}{llll}\text { Halsizlik } & 124 & 28,3\end{array}$

$\begin{array}{lll}\text { Döküntü } & 290 & 66,3\end{array}$

COVID-19 hastalığından korunmak için hastalarınıza neler önerirsiniz?

$\begin{array}{lll}\text { Maske kullanımı } & 415 & 94,9\end{array}$

$\begin{array}{lll}\text { El yıkama } & 436 & 99,7\end{array}$

$\begin{array}{lll}\text { Toplu alanlardan uzak durma } \quad 436 & 99,7\end{array}$

İmmün sistemi güçlendirici ilaç ve gıda katkıları $\quad 146 \quad 33,4$

COVID-19 için bağışıklık destekleyici ilaç öneriyor musunuz?

Tedavi önermiyorum 16537,7

$\begin{array}{lll}\text { Probiyotikler } & 93 & 21,2\end{array}$

$\begin{array}{lll}\text { Multivitaminler } & 162 & 37,1\end{array}$

Çinko $218 \quad 49,8$

$\begin{array}{lrr}\text { Beta glukan } & 86 & 19,6\end{array}$

Omega-3 desteği $\quad 66 \quad 15,1$

SF ile ağız burun temizliği $\quad 45 \quad 10,3$

COVID-19 gündelik yaşamınızı etkiledi mi?

Değişiklik olmadı 30,7

Seyahatlerimi kısıtladım $\quad 394 \quad 90,6$

Kongre programımı değiştirdim $\quad 242 \quad 55,4$

$\begin{array}{llll}\text { Ev için gıda ve su depoladım } & 144 & 32,9\end{array}$

Çocuğumu okula göndermiyorum $\quad 271 \quad 62$

$\begin{array}{lll}\text { İzin/işten ayrılmayı düşünüyorum } & 107 & 24,4\end{array}$

COVID-19 şüpheli hasta baktınız mı?

Evet

31171,2

COVID-19 şüpheli hasta sevk ettiniz mi?

Evet

$113 \quad 25,9$ 
Tablo 3: Katılımcıların sorulara verdikleri cevapların dağılımı.

\begin{tabular}{|c|c|c|}
\hline & Sayı (n) & $\%$ \\
\hline & 437 & \\
\hline \multicolumn{3}{|c|}{$\begin{array}{l}\text { COVID-19'un en yaygın semptomları ateş } \\
\text { yorgunluk ve kuru öksürüktür }\end{array}$} \\
\hline Doğru & 435 & 99,5 \\
\hline Yanlış & 1 & 0,2 \\
\hline Bilmiyorum & 1 & 0,2 \\
\hline \multicolumn{3}{|c|}{ Hastaların $\% \mathbf{8 0}^{\prime} i$ tedaviye ihtiyaç duymadan iyileşir } \\
\hline Doğru & 420 & 96,2 \\
\hline Yanlış & 12 & 2,7 \\
\hline Bilmiyorum & 5 & 1,1 \\
\hline \multicolumn{3}{|c|}{ COVID-19 etkeninin inkübasyon süresi nedir? } \\
\hline 2-14 gün & 406 & 92,9 \\
\hline Yanlış cevaplar & 31 & 7,1 \\
\hline \multicolumn{3}{|c|}{ COVID-19 etkeninin ana konağı hangisidir? } \\
\hline Yarasalar & 433 & 99,1 \\
\hline Yanlış cevaplar & 4 & 0,9 \\
\hline \multicolumn{3}{|c|}{ COVID-19 etkeninin ara konağı hangisidir? } \\
\hline Pangolin & 144 & 33 \\
\hline Yanlış cevaplar & 293 & 67 \\
\hline \multicolumn{3}{|c|}{ Gebelerden fetüse COVID-19 bulaş riski var mıdır? } \\
\hline Vardır & 176 & 40,3 \\
\hline Yoktur & 206 & 47,1 \\
\hline Bilmiyorum & 55 & 12,6 \\
\hline \multicolumn{3}{|c|}{ COVID-19 pozitif anne sütü ile bulaş riski var mıdır? } \\
\hline Vardır & 116 & 26,5 \\
\hline Yoktur & 283 & 64,8 \\
\hline Bilmiyorum & 38 & 8,7 \\
\hline \multicolumn{3}{|c|}{ COVID-19 hasta izolasyon süresi kaç gündür? } \\
\hline Doğru (14 gün) & 340 & 77,8 \\
\hline Yanlış & 97 & 22,2 \\
\hline \multicolumn{3}{|c|}{ Olguların yüzde kaçı hafif kliniğe sahiptir? } \\
\hline Doğru (\%50-80) & 392 & 89,7 \\
\hline Yanlış cevaplar & 45 & 10,3 \\
\hline \multicolumn{3}{|c|}{ COVID-19 için belirtilen mortalite oranı yüzde kaçtır? } \\
\hline Doğru (\%1-3) & 328 & 75,1 \\
\hline Yanlış cevaplar & 109 & 24,9 \\
\hline
\end{tabular}

Dünyadaki farklı örneklere baktığımızda, COVID-19 pandemisinde tıp eğitimi, mezuniyet öncesi ve sonrası eğitimde çevrimiçi yöntemler başarılı gibi görünmektedir (8-10). Aslında tıp eğitiminde daha öncesinde de kullanılan çevrimiçi yöntemlerin ağırlığı artmışa benzemektedir, ilginç olan mezuniyet öncesi eğitimde de YouTube ve canlı dersler diğer çevrimiçi yöntemlere göre en başarılı seçenekler arasındadır, yine de etkinliğinin yüz yüze eğitim kadar olmadığı öğrenciler tarafindan belirtilmektedir (7).

\section{Sonuç}

Bildiğimiz kadarı çalışmamız ile çocuk sağlığı alanında COVID-19 pandemisi sırasında mezuniyet sonrası interaktif eğitimle ilgili ilk anket çalışmasıdır. Özellikle bilgiye ulaşımı asimetrik olabilecek, periferde çalışan veya yoğun iş yükü nedeni ile gün içinde eğitim ve klasik bilgi öğrenme kaynaklarına yeterli zaman ayıramayan meslektaşlarımız için bu tür uygulamalar bir olasılık penceresi yaratmaktadır.

Etik Komite Onayı: Bu çalışma Memorial Şişli Hastanesi Etik Kurul'u tarafindan onaylandı (26.02.2021/08).

Bilgilendirilmiş Onam: Katılımcılardan bilgilendirilmiş onam alınmıştır.

Hakem Değerlendirmesi: Dış bağımsız.

Çıkar Çatışması: Yazarlar çıkar çatışması beyan etmemişlerdir.

Finansal Destek: Yazarlar finansal destek beyan etmemişlerdir.

Ethics Committee Approval: This study was approved by the ethics committee of Memorial Şişli Hospital (26.02.2021/08).

Informed Consent: Written consent was obtained from the participants.

Peer Review: Externally peer-reviewed

Conflict of Interest: Authors declared no conflict of interest.

Financial Disclosure: Authors declared no financial support.

\section{KAYNAKLAR/REFERENCES}

1. WHO Coronavirus Disease (COVID-19) Dashboard. Erişim linki: URL: https://COVID-19.who.int/ (Son erişim tarihi: 3.5.2021).

2. Sağlık Bakanlığı COVID-19 bilgilendirme sayfası. Erişim linki: URL: https://COVID-19.saglik.gov.tr/ (Son erişim tarihi: 3.5.2021).

3. World Health Organization. Coronavirus disease (COVID-19) situation report. Weekly Epidemiological Update. (Data as received by WHO from national authorities, as of 10 am CEST 13 September 2020) Pp:1-34. Erişim linki: URL: https://www.who.int/ docs/ default-source/coronaviruse/situation-reports/20200914- weeklyepi-update 5.pdf?sfvrsn=cf929d04 (Son erişim tarihi: 3.5.2021).

4. Mahase E. Covid-19: What do we know so far about a vaccine? BMJ 2020;27(369):1-2. doi:10.1136/bmj.m1679.

5. Oygar PD, Büyükçam A, Şahbudak Bal Z, Dalgıç N, Bozdemir ŞE, Karbuz A ve ark. COVID-19 pandemisinde enfeksiyon kontrol çalışmaları çerçevesinde çocuk hastalarla çalışan sağlık personeli eğitimi. J Pediatr Inf 2020;14(4):195-200. DOI:10.5578/ced.70235.

6. Gönüllü E, Soysal A, Can I, Tutak E, Tunç T, Yıldız I ve ark. The Use of Social Network in Daily Pediatric Practice and Education: Turkish Pediatric Atelier. Int J Pediatr 2020(7301309);1-7. DOI:10.1155/2020/7301309.

7. The Jamovi Project (2021): Jamovi istatistik programı- sürüm 1.8. Erişim linki: URL: http://www.jamovi.org.

8. Yadala S, Nalleballe K, Sharma R, Lotia M, Kapoor N, Veerapaneni $K D$, et al. Resident Education During COVID-19 Pandemic: Effectiveness of Virtual Electroencephalogram Learning. Cureus 2020;12(10):e11094. DOI 10.7759/cureus.11094.

9. Dost S, Hossain A, Shehab M, Abdelwahed A, Al-Nusair L. Perceptions of medical students towards online teaching during the COVID-19 pandemic: a national cross-sectional survey of 2721 UK medical students. BMJ Open 2020;10(11);1-10: e042378. DOI: 10.1136/bmjopen-2020-042378.

10. Amparore D, Claps F, Cacciamani GE, Esperto F, Fiori C, Liguori G ve ark. Impact of the COVID-19 pandemic on urology residency training in Italy. Minerva Urol Nefrol 2020;72(4):505-9. doi: 10.23736/S0393-2249.20.03868-0. 